Received 00th January 20xx, Accepted 00th January 20xx DOI: $10.1039 / x 0 x x 00000 x$

\title{
Dysprosium(III) compounds assembled via a versatile ligand incorporating salicylic hydrazide and 8-hydroxyquinolin units: Syntheses, structures and magnetic properties
}

\author{
Li Zhang, ${ }^{\mathrm{a}, \mathrm{d}}$ Vincent Montigaud, ${ }^{\mathrm{b}}$ Boris Le Guennic, ${ }^{* \mathrm{~b}}$ Peng Zhang*c and Jinkui Tang*a
}

\begin{abstract}
Assembly of dysprosium(III) salts with a multidentate ligand $\mathrm{H}_{3} \mathrm{~L}$ ((2-hydroxy)- $\mathrm{N}^{\prime}-((8$-hydroxyquinolin-2-yl)methylene)benzohydrazide) affords a variety of products with different topological structures, namely $\left[\mathrm{Dy}\left(\mathrm{H}_{2} \mathrm{~L}\right)(\mathrm{HL})\right] \cdot \mathrm{CH}_{3} \mathrm{OH}(\mathbf{1})$, $\left[D y_{2}(\mathrm{HL})_{2}\left(\mathrm{C}_{6} \mathrm{H}_{5} \mathrm{COO}\right)_{2}\left(\mathrm{CH}_{3} \mathrm{OH}\right)_{2}\right] \cdot 3 \mathrm{CH}_{3} \mathrm{OH}$ (2), $\left[\mathrm{Dy}_{2}(\mathrm{HL})_{2}\left(\mathrm{NO}_{3}\right)_{2}(\mathrm{DMF})_{4}\right] \cdot 4 \mathrm{DMF}$ (3), [Dy $\left.\mathrm{LL}_{4}\left(\mathrm{CH}_{3} \mathrm{OH}\right)_{4}\right] \cdot 2 \mathrm{CH}_{3} \mathrm{OH} \cdot 4 \mathrm{H}_{2} \mathrm{O}$ (4) and $\left(\left[\mathrm{Dy}{ }_{4}(\mathrm{HL})_{4}\left(\mathrm{C}_{6} \mathrm{H}_{5} \mathrm{COO}\right)_{4}\left(\mathrm{CH}_{3} \mathrm{OH}\right)\left(\mathrm{H}_{2} \mathrm{O}\right)\right] \cdot 2 \mathrm{CH}_{3} \mathrm{OH} \cdot \mathrm{CH}_{3} \mathrm{CN}_{2} \cdot \mathrm{H}_{2} \mathrm{O}\right)_{n}(5)$. The versatile and flexible coordination modes of phenoxo groups from salicylic hydrazide prove to be a key factor in the assembly of corresponding structures depending upon the reaction conditions. It is noteworthy that ligands $\mathrm{HL}^{2-}$ act as a long-distance link and further connect the Dy ${ }_{2}$ fragments into an infinite 1D chain due to the conformational flexibility resulting from the rotatable $\mathrm{C}-\mathrm{C}$ bond in $\mathbf{5}$. Furthermore, the magnetic measurements were performed on all complexes. The dc magnetic susceptibility data evidence distinct magnetic coupling interactions in the dinuclear complexes $\mathbf{2}$ (antiferromagnetic) and $\mathbf{3}$ (ferromagnetic) despite their similar structures, and only complex 3 shows slow relaxation behavior of magnetization. Ab initio calculations and electrostatic potential analysis on complexes $\mathbf{2}, \mathbf{3}$, and three other complexes $(\mathbf{6}, \mathbf{7}, \mathbf{8})$ incorporating different kinds of ligands reveal the important interrelationship of magnetic anisotropy, magnetic coupling interactions and SMM properties.
\end{abstract}

\section{Introduction}

Single-molecule magnets (SMMs) showing slow relaxation of magnetization deriving from molecular-based blocking anisotropy have been a burgeoning field of intense interest of physical, chemical and material scientists over the past two decades on account of their exotic technological applications in high-density information storage, quantum computing, and spintronics. ${ }^{1-8}$ Since the seminal discovery that the doubledecker complex $\left[\mathrm{Tb}(\mathrm{Pc})_{2}\right]^{-} \cdot\left(\mathrm{Bu}_{4} \mathrm{~N}\right)^{+}\left(\mathrm{Pc}^{2-}=\right.$ phthalocyaninic $)$ shows slow relaxation of the magnetization at low temperatures, ${ }^{9}$ considerable attention is being paid to elaborate high-barrier SMMs via using $4 f$ ions as a result of their unparalleled magnetic anisotropy arising from the unquenched orbital angular momentum in ligand field. ${ }^{10}, 11$ Certainly, dysprosium(III) ion plays a crucial role in the exploitation of lanthanide-based SMMs because of the joint cooperation of large magnetic ground states, single-ion anisotropy and spinparity effect in Kramers ions (odd number of $4 f$ electrons),

a. State Key Laboratory of Rare Earth Resource Utilization, Changchun Institute of Applied Chemistry, Chinese Academy of Sciences, Changchun 130022, P. R. China b. Univ Rennes, CNRS, ISCR (Institut des Sciences Chimiques de Rennes) - UMR 6226, F-35000 Rennes, France

c. School of Chemistry \& Chemical Engineering, Shaanxi Normal University, Xi'an, Shaanxi 710062, P. R. China

d. Key Laboratory of Synthetic and Natural Functional Molecule Chemistry of the Ministry of Education, College of Chemistry and Materials Science, Northwest University, Xi'an 710069, P. R. China

† Footnotes relating to the title and/or authors should appear here.

Electronic Supplementary Information (ESI) available: [details of any supplementary information available should be included here]. See DOI: 10.1039/x0xx00000x which thus are responsible for numerous ground-breaking results. ${ }^{12-21}$ In particular, judicious optimization of the crystal field resulted in magnetic bistability persisting up to $80 \mathrm{~K}$ recently in a dysprosium metallocene, which allows access to the operating temperature above liquid nitrogen, a critical point to the practical application. ${ }^{22}$

Notably, Dy-based SMMs of varying nuclearities and topologies range over as single, dimeric, ${ }^{23-26}$ triangular, $^{5,} 27$ cube, $^{28,} 29$ rhombus, $^{30}$ defect-dicubane, ${ }^{31-33}$ tetrahedron, ${ }^{34,} 35$ square-based pyramid, 20,36 wheel, ${ }^{37-39}$ nanotubes, ${ }^{40}$ and so forth. To the best of our knowledge, one of the most important factors that realize the tailor-made of functional SMMs is the design of organic ligands. Progress in the field makes clear that hydrazone Schiff-base ligands are quite suitable to construct aesthetically structural dysprosium-based SMMs showing typical relaxation dynamics. ${ }^{41,42}$ Such rigid multidentate ligands usually possess several coordination pockets to encapsulate lanthanide ions formed by a sequence of oxygen and nitrogen donors, while various conformations can be derived from the facile keto-enol tautomerism and isomerism from the rotatable $\mathrm{C}-\mathrm{C}$ bond which favours versatile bridging modes through $\mu-\mathrm{O}$ connections. Here we designed a aroylhydrazone ligand (2hydroxy)-N'-((8-hydroxyquinolin-2-yl)methylene)-

benzohydrazide $\left(\mathrm{H}_{3} \mathrm{~L}\right.$, Scheme 1$)$ possessing a flexible phenoxo group of salicylic hydrazide with various coordination behaviours relying on the reaction conditions. Therefore, a series of mononuclear, dinuclear and tetranuclear Dy'II assemblies as well as 1D linear Dy'll polymer, formulated as $\left[\mathrm{Dy}\left(\mathrm{H}_{2} \mathrm{~L}\right)(\mathrm{HL})\right] \cdot \mathrm{CH}_{3} \mathrm{OH}$ 
$\left[\mathrm{Dy}_{2}(\mathrm{HL})_{2}\left(\mathrm{C}_{6} \mathrm{H}_{5} \mathrm{COO}\right)_{2}\left(\mathrm{CH}_{3} \mathrm{OH}\right)_{2}\right] \cdot 3 \mathrm{CH}_{3} \mathrm{OH}$

$\left[\mathrm{Dy}{ }_{2}(\mathrm{HL})_{2}\left(\mathrm{NO}_{3}\right)_{2}(\mathrm{DMF})_{4}\right] \cdot 4 \mathrm{DMF}$

$\left[\mathrm{Dy}_{4} \mathrm{~L}_{4}\left(\mathrm{CH}_{3} \mathrm{OH}\right)_{4}\right] \cdot 2 \mathrm{CH}_{3} \mathrm{OH} \cdot 4 \mathrm{H}_{2} \mathrm{O}$

$\left(\left[\mathrm{Dy}_{4}(\mathrm{HL})_{4}\left(\mathrm{C}_{6} \mathrm{H}_{5} \mathrm{COO}\right)_{4}\left(\mathrm{CH}_{3} \mathrm{OH}\right)\left(\mathrm{H}_{2} \mathrm{O}\right)\right] \cdot 2 \mathrm{CH}_{3} \mathrm{OH} \cdot \mathrm{CH}_{3} \mathrm{CN} \cdot \mathrm{H}_{2} \mathrm{O}\right)_{\mathrm{n}}$ were isolated. The magnetic measurements were carried out on all complexes. In particular, dc magnetic susceptibility data evidences distinct magnetic coupling interactions in the dinuclear complexes $\mathbf{2}$ and $\mathbf{3}$, and only complex $\mathbf{3}$ shows slow relaxation behaviour of magnetization despite the similar structures. To get insight into the key factors of hydrazone Schiff-base ligands in determining magnetic properties of Dybased SMMs, ab initio calculations and electrostatic potential analysis are performed on complexes 2, 3, and three other complexes $(\mathbf{6}, \mathbf{7}, \mathbf{8})$, where four kinds of ligands with similar structural features but different charge distribution and bridging donors are incorporated specially into deprotonated enolic, quinolinic/phenoxo, and alkoxido oxygen donors showing the gradually increasing electron-donating ability. The results reveal the important interrelationship of magnetic anisotropy, magnetic coupling interactions and SMM properties. Here the magnetic anisotropy is determined by charge distribution on ligands, thus the angles of easy axes to Dy...Dy connecting line allow the calculations of magnetic dipolar interactions $\left(J_{\text {dip }}\right)$ and further affect the magnitude of magnetic exchange coupling $J_{\text {exch }}$, which results in a combined effect on magnetic coupling interactions between Dy centres $\left(J_{\text {total }}\right)$.

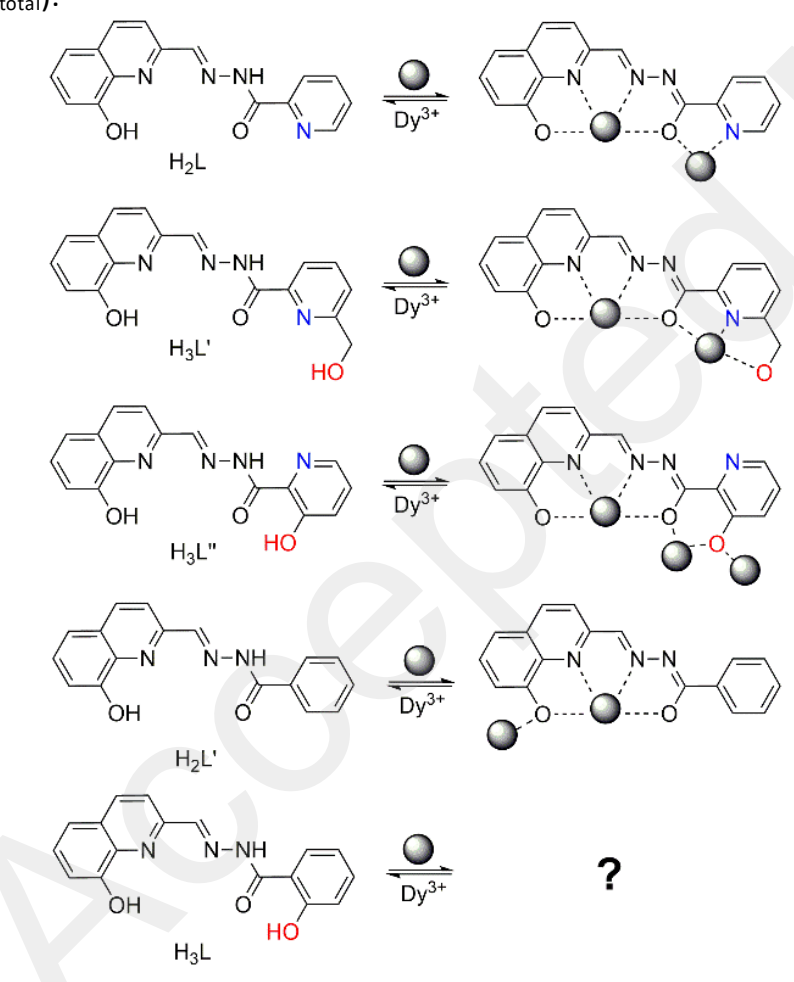

Scheme 1 Structure of ligand $\mathrm{H}_{3} \mathrm{~L}$ and the related ligands as well as their coordination modes.

\section{Experimental section}

(2), Materials and Physical Measurements. All reagents and solvents were of analytical reagent grade and were used as commercially obtained without further purification. Dy $\left(\mathrm{C}_{6} \mathrm{H}_{5} \mathrm{COO}\right)_{3}$ were prepared according to a literature procedure described elsewhere. ${ }^{43}$ Elemental analysis (C, $\mathrm{H}$, and N) were performed with a Perkin-Elmer 2400 analyzer. FTIR spectra were recorded with a Perkin-Elmer Fourier transform infrared spectrophotometer using the reflectance technique $\left(4000-300 \mathrm{~cm}^{-1}\right)$. Samples were prepared as $\mathrm{KBr}$ disks. Magnetic susceptibility measurements were carried out on a Quantum Design MPMS-XL7 SQUID magnetometer equipped with a 7 T magnet. The direct current (dc) measurements were collected with an external magnetic field of 1000 Oe in the temperature range 1.9-300 K, and the alternating-current (ac) measurements were carried out in a $3.0 \mathrm{Oe}$ ac field oscillating at different frequencies from 1 to $1500 \mathrm{~Hz}$. The experimental magnetic susceptibility data are corrected for the diamagnetism estimated from Pascal's tables ${ }^{44}$ and sample holder calibration.

Crystallographic data collection and refinement. Crystallographic data of complexes 1-5 were collected on a Bruker Apex II CCD diffractometer with graphite monochromated Mo-K $\alpha$ radiation ( $\lambda=0.71073 \AA$ ) at 296 (2) K. The structure was solved by direct methods by means of SHELXS-97 45 and refined on $F^{2}$ by full-matrix least squares in the Olex2 package. ${ }^{46}$ The location of Dy atoms was easily determined, and $\mathrm{O}, \mathrm{N}$, and $\mathrm{C}$ atoms were subsequently determined from the difference Fourier maps. All non-hydrogen atoms were refined with anisotropic thermal parameters. The $\mathrm{H}$ atoms were introduced in calculated positions and refined with fixed geometry with respect to their carrier atoms. CCDC 1021519 (1), 1021520 (2), 1021521 (3), 1021522 (4), and 1021523 (5) contain the supplementary crystallographic data for this paper. These data can be obtained free of charge from the Cambridge Crystallographic Data Centre via www.ccdc.cam.ac.uk/data_request/cif.

Synthesis of $\mathrm{H}_{3} \mathrm{~L}$. The Schiff-base ligand $\mathrm{H}_{3} \mathrm{~L}$ ((2-hydroxy)-N'((8-hydroxyquinolin-2-yl)methylene)-benzohydrazide) was synthesized by condensation of 2-hydroxybenzohydrazide and 8-hydroxyquinoline-2-carbaldehyde in a 1:1 ratio in methanol. ${ }^{47}$ The resultant orange precipitate was filtered off, washed with diethyl ether and dried to obtain orange powder in $70 \%$.

Synthesis of $\left[\mathrm{Dy}\left(\mathrm{H}_{2} \mathrm{~L}\right)(\mathrm{HL})\right] \cdot \mathrm{CH}_{3} \mathrm{OH}(1)$. $\mathrm{Dy}\left(\mathrm{ClO}_{4}\right)_{3} \cdot 6 \mathrm{H}_{2} \mathrm{O}(0.1$ $\mathrm{mmol}, 0.057 \mathrm{~g})$ was added to a suspension of $\mathrm{H}_{3} \mathrm{~L}(0.1 \mathrm{mmol}$, $0.031 \mathrm{~g})$ in $\mathrm{CH}_{3} \mathrm{OH} / \mathrm{CH}_{2} \mathrm{Cl}_{2}(10 \mathrm{~mL} / 5 \mathrm{~mL})$, followed by the adding of $\mathrm{KOH}(0.1 \mathrm{mmol}, 0.006 \mathrm{~g})$. The resultant dark red solution was stirred for $5 \mathrm{~h}$ and subsequently filtered. The filtrate was exposed to air to allow the slow evaporation of the solvent. Dark red blocks of $\mathbf{1}$ suitable for X-ray diffraction analysis were collected after 10 days. Yield: $15 \mathrm{mg}$ (19\%, based on Dy). Elemental analysis (\%) calcd for $\mathrm{C}_{35} \mathrm{H}_{27} \mathrm{DyN}_{6} \mathrm{O}_{7}: \mathrm{C}, 52.15, \mathrm{H}, 3.38$, $\mathrm{N}, 10.43$; found: $\mathrm{C}, 52.29, \mathrm{H}, 3.29, \mathrm{~N}, 10.63 . \mathrm{IR}\left(\mathrm{KBr}, \mathrm{cm}^{-1}\right): 3645$ (w), 3182 (br), $1606(\mathrm{~m}), 1588(\mathrm{~m}), 1542(\mathrm{w}), 1484(\mathrm{~s}), 1442(\mathrm{~m})$, $1358(\mathrm{~s}), 1336(\mathrm{~s}), 1306(\mathrm{~m}), 1252(\mathrm{~m}), 1216(\mathrm{~m}), 1171(\mathrm{w}), 1153$ $(\mathrm{m}), 1131(\mathrm{~m}), 1104(\mathrm{~m}), 1036(\mathrm{w}), 938(w), 901(w), 830(w)$, $737(m), 664(w), 592(w), 563(w), 534(w)$.

Synthesis of $\left[\mathrm{Dy}{ }_{2}(\mathrm{HL})_{2}\left(\mathrm{C}_{6} \mathrm{H}_{5} \mathrm{COO}\right)_{2}\left(\mathrm{CH}_{3} \mathrm{OH}\right)_{2}\right] \cdot 3 \mathrm{CH}_{3} \mathrm{OH}$ (2). $\operatorname{Dy}\left(\mathrm{C}_{6} \mathrm{H}_{5} \mathrm{COO}\right)_{3}(0.1 \mathrm{mmol}, 0.053 \mathrm{~g})$ was added to a suspension of 
$\mathrm{H}_{3} \mathrm{~L}$ (0.1 mmol, $0.031 \mathrm{~g}$ ) in $\mathrm{CH}_{3} \mathrm{OH} / \mathrm{CH}_{2} \mathrm{Cl}_{2}(10 \mathrm{~mL} / 5 \mathrm{~mL})$, followed by the adding of $\mathrm{Et}_{3} \mathrm{~N}(0.2 \mathrm{mmol}, 0.028 \mathrm{~mL})$. The resultant orange solution was stirred for $5 \mathrm{~h}$ and subsequently filtered. The filtrate was exposed to air to allow the slow evaporation of the solvent. Dark orange blocks of $\mathbf{2}$ suitable for X-ray diffraction analysis were collected after 5 days. Yield: $20 \mathrm{mg}$ (30\%, based on Dy). Elemental analysis (\%) calcd for $\mathrm{C}_{53} \mathrm{H}_{52} \mathrm{Dy}_{2} \mathrm{~N}_{6} \mathrm{O}_{15}$ : C, 47.58, H, 3.92, N, 6.28; found: C, 47.35, H, 3.97, N, 6.34. IR ( KBr, $\mathrm{cm}^{-1}$ ): 3615 (w), 3353 (br), $1598(\mathrm{~m}), 1580(\mathrm{~m}), 1544(\mathrm{w}), 1489$ (s), $1474(\mathrm{~s}), 1446(\mathrm{~m}), 1404(\mathrm{~s}), 1362(\mathrm{~s}), 1332(\mathrm{~s}), 1309(\mathrm{~m})$, $1256(\mathrm{~m}), 1190(\mathrm{w}), 1175(\mathrm{w}), 1154(\mathrm{~m}), 1099(\mathrm{~m}), 1076(\mathrm{w})$, $1030(w), 970(w), 938(w), 910(w), 858(w), 835(m), 761(m)$, $736(w), 714(m), 671(w), 566(w)$.

Synthesis of $\left[\mathrm{Dy}_{2}(\mathrm{HL})_{2}\left(\mathrm{NO}_{3}\right)_{2}(\mathrm{DMF})_{4}\right] \cdot 4 \mathrm{DMF} \quad$ (3). $\operatorname{Dy}\left(\mathrm{NO}_{3}\right)_{3} \cdot 6 \mathrm{H}_{2} \mathrm{O}(0.1 \mathrm{mmol}, 0.046 \mathrm{~g})$ was added to a suspension of $\mathrm{H}_{3} \mathrm{~L}(0.1 \mathrm{mmol}, 0.031 \mathrm{~g})$ in $\mathrm{CH}_{3} \mathrm{OH} / \mathrm{CH}_{2} \mathrm{Cl}_{2}(10 \mathrm{~mL} / 5 \mathrm{~mL})$, followed by the adding of $\mathrm{Et}_{3} \mathrm{~N}(0.3 \mathrm{mmol}, 0.042 \mathrm{~mL})$. The resultant orange solution was stirred for $5 \mathrm{~h}$ and subsequently filtered. The resulting precipitation was dried and redissolved in DMF (10 mL). Diethyl ether was allowed to diffuse slowly into the solution at room temperature and orange rhombic single crystals of 3 were formed in 5 days. Yield: $28 \mathrm{mg}$ (34\%, based on Dy). Elemental analysis (\%) calcd for $\mathrm{C}_{58} \mathrm{H}_{78} \mathrm{Dy}{ }_{2} \mathrm{~N}_{16} \mathrm{O}_{20}$ : C, 42.36, $\mathrm{H}, 4.78, \mathrm{~N}, 13.63$; found: $\mathrm{C}, 42.21, \mathrm{H}, 4.82, \mathrm{~N}, 13.75$. IR (KBr, $\mathrm{cm}$ 1): $2931(w), 2809(w), 2602(w), 1650(s), 1597(m), 1547(w)$, 1489 (s), 1449 (s), $1384(\mathrm{~m}), 1360$ (s), 1332 (s), 1304 (s), 1273 $(\mathrm{m}), 1254(\mathrm{~m}), 1216(\mathrm{~m}), 1180(\mathrm{w}), 1160(\mathrm{~m}), 1103(\mathrm{~m}), 1082$ (m), $1038(w), 966(w), 927(w), 900(w), 849(w), 787(w), 768$ $(\mathrm{m}), 737(\mathrm{~m}), 702(\mathrm{w}), 674(\mathrm{~m}), 569(\mathrm{w})$.

Synthesis of $\left[\mathrm{Dy}_{4} \mathrm{~L}_{4}\left(\mathrm{CH}_{3} \mathrm{OH}\right)_{4}\right] \cdot \mathbf{2} \mathrm{CH}_{3} \mathrm{OH} \cdot \mathbf{4} \mathrm{H}_{2} \mathrm{O}$ (4). The orange filtrate obtained in $\mathbf{3}$ was exposed to air to allow the slow evaporation of the solvent. Red blocks of $\mathbf{4}$ suitable for X-ray diffraction analysis were collected after one week. Yield: $12 \mathrm{mg}$ (23\%, based on Dy). Elemental analysis (\%) calcd for $\mathrm{C}_{74} \mathrm{H}_{72} \mathrm{Dy}_{4} \mathrm{~N}_{12} \mathrm{O}_{22}$ : C, 41.70, $\mathrm{H}, 3.40, \mathrm{~N}, 7.89$; found: $\mathrm{C}, 41.50, \mathrm{H}$, 3.37, N, 7.93. IR (KBr, cm $\left.{ }^{-1}\right): 3368(\mathrm{br}), 1629(\mathrm{w}), 1585(\mathrm{~m}), 1563$ $(\mathrm{m}), 1481(\mathrm{~s}), 1453(\mathrm{~m}), 1426(\mathrm{~m}), 1381(\mathrm{~m}), 1334(\mathrm{~m}), 1309(\mathrm{~m})$, $1274(w), 1254(m), 1142(w), 1104(m), 1062(m), 973(w), 923$ (w), $870(w), 838(m), 756(m), 671(m), 582(w)$.

Synthesis

of

([Dy $\left.\left.{ }_{4}(\mathrm{HL})_{4}\left(\mathrm{C}_{6} \mathrm{H}_{5} \mathrm{COO}\right)_{4}\left(\mathrm{CH}_{3} \mathrm{OH}\right)\left(\mathrm{H}_{2} \mathrm{O}\right)\right] \cdot 2 \mathrm{CH}_{3} \mathrm{OH} \cdot \mathrm{CH}_{3} \mathrm{CN} \cdot \mathrm{H}_{2} \mathrm{O}\right)_{n}$ (5). $\mathrm{Dy}\left(\mathrm{C}_{6} \mathrm{H}_{5} \mathrm{COO}\right)_{3}(0.1 \mathrm{mmol}, 0.053 \mathrm{~g})$ was added to a suspension of $\mathrm{H}_{3} \mathrm{~L}(0.1 \mathrm{mmol}, 0.031 \mathrm{~g})$ in $\mathrm{CH}_{3} \mathrm{OH} / \mathrm{CH}_{3} \mathrm{CN}(5 \mathrm{~mL} / 10 \mathrm{~mL})$, followed by the adding of $\mathrm{NaHCO}_{3}(0.1 \mathrm{mmol}, 0.008 \mathrm{~g})$. The resultant orange solution was stirred for $5 \mathrm{~h}$ and subsequently filtered. The filtrate was exposed to air to allow the slow evaporation of the solvent. Red needles of $\mathbf{5}$ suitable for X-ray diffraction analysis were collected after two weeks. Yield: $8 \mathrm{mg}(13 \%$, based on Dy). Elemental analysis (\%) calcd for $\mathrm{C}_{101} \mathrm{H}_{83} \mathrm{Dy}_{4} \mathrm{~N}_{13} \mathrm{O}_{25}$ : C, 47.97, H, 3.31, N, 7.20; found: C, 47.86, H, 3.35, N, 7.32. IR ( $\mathrm{KBr}$, $\mathrm{cm}^{-1}$ ): $3616(\mathrm{w}), 3370(\mathrm{br}), 3064(\mathrm{w}), 1601(\mathrm{~m}), 1579(\mathrm{~m}), 1544$ $(\mathrm{m}), 1488(\mathrm{~s}), 1446(\mathrm{~m}), 1403(\mathrm{~s}), 1362(\mathrm{~s}), 1331(\mathrm{~s}), 1309(\mathrm{~m})$, $1255(\mathrm{~s}), 1189(\mathrm{w}), 1154(\mathrm{~m}), 1098(\mathrm{~m}), 1076(\mathrm{w}), 1025(\mathrm{w}), 938$ $(w), 910(w), 857(w), 834(m), 760(m), 714(m), 670(w), 565$ (w).

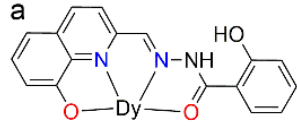

1.1111

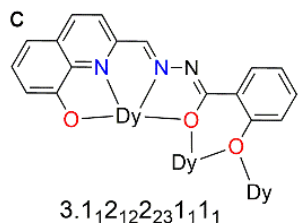

$3.1_{1} 2_{12} 2_{23} 1_{1} 1_{1}$ Dy

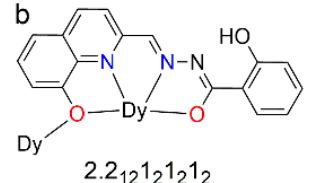

d

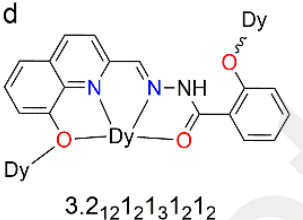

Scheme 2 Coordination modes of $\mathrm{H}_{3} \mathrm{~L}$ indicated by the Harris Notation $^{48}$ in complexes 1-5.

\section{Results and Discussion}

Syntheses. The o-vanilloylhydrazone and picolinoylhydrazone ligands along with their derivatives have been widely used and proven to be an effective strategy for developing Dy-SMMs. ${ }^{49-51}$ On the other hand, the 8hydroxyquinoline unit possessing one pyridine donor and one phenolate unit can function as chelating and bridging agent, and is thus an ideal building block in molecular multimetallic ensembles. ${ }^{52}$ Therefore, the ligands combining the above two components are expected to blossom into achieving pure dysprosium-based systems with pleasing structural motif and magnetic properties. In fact, several typical examples have been reported with the ligands in Scheme 1 by our group and others, respectively, showing a wide range of nuclearities from two to eight metal centres. ${ }^{25}$, 30, 53-55 However, systematic investigations on this kind of ligands have not been performed. Here complexes 1-5 in Fig. 1 were successfully synthesized by reacting $\mathrm{H}_{3} \mathrm{~L}$ with the corresponding dysprosium salts in different solvents under various bases. Among these, the interesting structural feature lies in the flexible coordination patterns of phenoxo groups from salicylic hydrazide (red rectangle in Fig. 1), depending on the reaction conditions. The reaction of $\mathrm{H}_{3} \mathrm{~L}$ and $\mathrm{Dy}\left(\mathrm{NO}_{3}\right)_{3} \cdot 6 \mathrm{H}_{2} \mathrm{O}$, in the presence of three equivalents of triethylamine in a mixture of methanol and dichloromethane $(v / v=2: 1)$ produces $[2 \times 2]$ grid-like $\mathrm{Dy}_{4}$ molecule (4), in which fully deprotonated ligand L $^{3-}$ bridges three dysprosium centres through their enolic oxygen and phenoxo oxygen atoms (pink). In contrast, $\mathrm{C}-\mathrm{C}$ rotation leads to the trans-conformation isomerism of phenoxo oxygen atoms to enolic oxygen atom in the formation of other compounds. In particular, a linear 1D Dy"ll chain (5) was obtained via connecting two distant $\mathrm{Dy}_{2}$ fragments by the phenoxo oxygen atoms when base $\mathrm{NaHCO}_{3}$ was present. The phenoxo groups remain uncoordinated and offer little assistance in the course of assembly of mononuclear and dinuclear complexes 1-3. The structural data and refinement details are summarized in Table S1, and selected bond lengths and angles are listed in Table S2.

Crystal structure. Crystal structure of 1 . The reaction of Dy $\left(\mathrm{ClO}_{4}\right)_{3} \cdot 6 \mathrm{H}_{2} \mathrm{O}$ with $\mathrm{H}_{3} \mathrm{~L}$ in methanol/dichloromethane (2:1 ratio), in the presence of $\mathrm{KOH}$, affords dark red crystals of $\mathbf{1}$, which crystallizes in the monoclinic space group $P 2_{1} / c$ with $Z=$ 
4. The single-crystal X-ray structure of complex $\mathbf{1}$ is represented in Fig. 2a and the asymmetric molecule consists of a Dy"l' ion, a

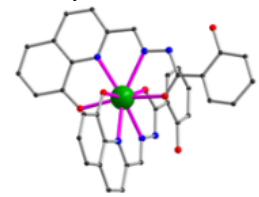

1 Mononuclear Dy
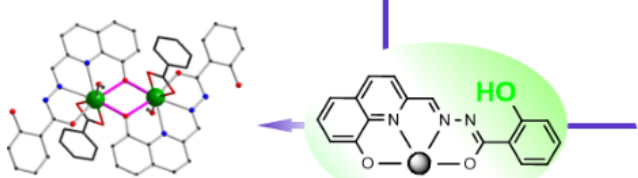

2 Dinuclear $\mathrm{Dy}_{2}$

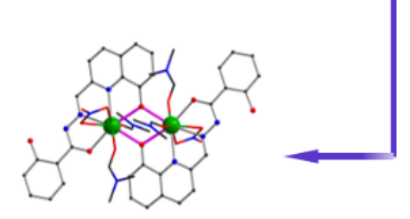

3 Dinuclear $\mathrm{Dy}_{2}$ mono-deprotonated $\mathrm{H}_{2} \mathrm{~L}^{-}$ligand, a di-deprotonated $\mathrm{HL}^{2-}$ - ligand together with an uncoordinated methanol molecule.
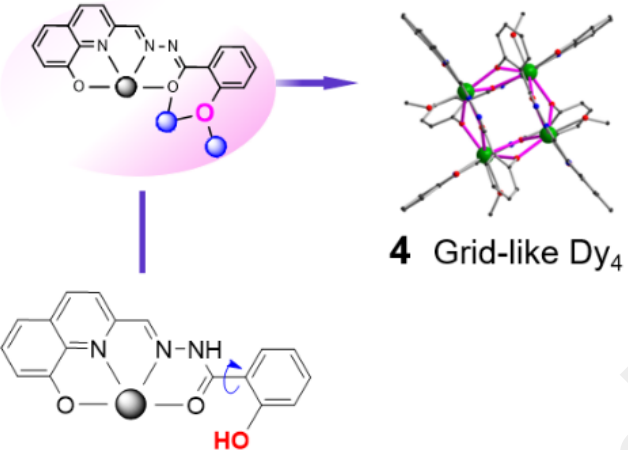

4 Grid-like $\mathrm{Dy}_{4}$

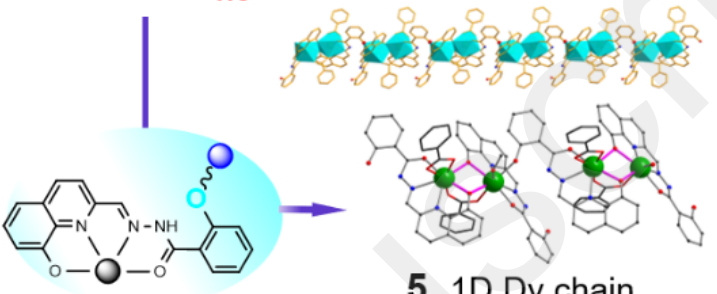

5 1D Dy chain

Fig. 1 Various products from ligand $\mathrm{H}_{3} \mathrm{~L}$ in different conditions, highlighting three diverse coordination patterns of phenoxo groups with vivid colours.

The metal centre is chelated concurrently by two $\mathrm{N}_{2} \mathrm{O}_{2}$ coordination pockets (Scheme 2a) of $\mathrm{H}_{2} \mathrm{~L}^{-}$and $\mathrm{HL}^{2-}$ ligands in a crisscross fashion, leading to a pseudo-2-fold axis (Fig. 2b). Two tetradentated ligands saturate the eight-coordinated sphere with an effective geometry of distorted shape among triangular dodecahedron $\left(D_{2 \mathrm{~d}}\right)$, snub disphenoid $\left(D_{2 \mathrm{~d}}\right)$, and biaugmented trigonal prism $\left(C_{2 v}\right)$ but closer to snub disphenoid (Fig. 2C), as determined by continuous shape measure theory and SHAPE software (Table S3). ${ }^{56}$ The crystal packing arrangement of complex 1 along the crystallographic c-axis exhibits a zigzag pattern with the nearest intermolecular Dy..Dy distance of $7.544 \AA$ A which is shown in Fig. $\mathrm{S} 1.57$
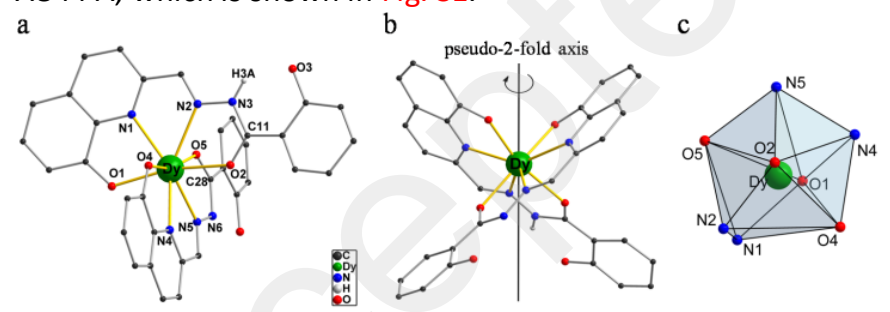

Fig. 2 a) Molecular structure of complex 1 with solvents and hydrogen atoms omitted for clarity; b) Arrangement of $\mathrm{H}_{2} \mathrm{~L}^{-}$and $\mathrm{HL}^{2-}$ ligands in a crisscross fashion; $\mathrm{c}$ ) Eight-coordinate distorted geometry around Dy ion.

Crystal structure of $\mathbf{2}$. A procedure similar to that of $\mathbf{1}$ except that $\mathrm{Dy}\left(\mathrm{ClO}_{4}\right)_{3} \cdot 6 \mathrm{H}_{2} \mathrm{O}$ and $\mathrm{KOH}$ were replaced by $\mathrm{Dy}\left(\mathrm{C}_{6} \mathrm{H}_{5} \mathrm{COO}\right)_{3}$ and $\mathrm{Et}_{3} \mathrm{~N}$ yields dark orange blocks of 2 after 5 days. X-ray analysis performed on single crystals of complex $\mathbf{2}$ reveal that it crystallizes in the triclinic space group $P-1$ with $Z=1$. As shown in Fig. 3a, two dysprosium centres of the centrosymmetric $\mathbf{2}$ are bridged by two quinolinic oxygen groups (01 and O1A) of two antiparallel $\mathrm{HL}^{2-}$ ligands with Dy-O-Dy angles being $107.79(14)^{\circ}$ and Dy $\cdots$ Dy distance of 3.8013(5)Å. Nearly planar $\mathrm{HL}^{2-}$ ligand tends to bind Dy1 through quinolinic oxygen (O1), quinolinic nitrogen (N1), imino nitrogen (N2) and enolic oxygen atoms (O2) in a Harris Notation fashion 2.2 $2_{12} 1_{2} 1_{2} 1_{2}$ (Scheme $2 b$ ) and the coordination sphere of Dy 1 is completed by a bidentated benzoate ion and a methanol molecule, creating a closest ideal geometry of distorted triangular dodecahedral $\left(D_{2 \mathrm{~d}}\right)$ (Fig. 3b). In this molecule, the average Dy-O and Dy- $\mathrm{N}$ bond lengths are 2.363 and $2.466 \AA$, respectively. a

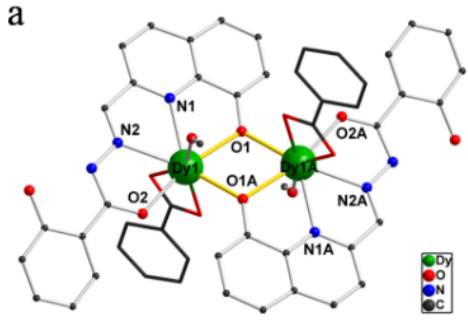

b

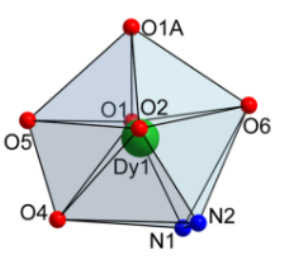

Fig. 3 a) Dinuclear structure of complex $\mathbf{2}$ with solvents and hydrogen atoms omitted for clarity; b) Distorted triangular dodecahedral geometry around the Dy1 ion in 2. Symmetry codes: $A,-x+1,-y,-z+1$.

Crystal structure of 3. A method of allowing diethyl ether to slowly diffuse into DMF solution of precipitation from the reaction of $\mathrm{Dy}\left(\mathrm{NO}_{3}\right)_{3} \cdot 6 \mathrm{H}_{2} \mathrm{O}$ with $\mathrm{H}_{3} \mathrm{~L}$ and $\mathrm{Et}_{3} \mathrm{~N}$ produces orange rhombic crystals of $\mathbf{3}$. Complex $\mathbf{3}$ crystallizes in the monoclinic space group $P 2_{1} / c$ with $Z=2$, whose structure is depicted in Fig. 4a. A pair of Dy'll ions individually residing in $\mathrm{N}_{2} \mathrm{O}_{2}$ coordination pocket are linked by two quinolinic oxygen atoms ( $\mathrm{O} 1$ and $\mathrm{O} 1 \mathrm{~A}$ ) of two antiparallel $\mathrm{HL}^{2-}$ ligands with Dy-O-Dy angles equal to $111.89(14)^{\circ}$ and Dy...Dy distance being 3.9523(7) Å. One bidentated nitrate and two terminal DMF molecules fulfil the 
$\mathrm{N}_{2} \mathrm{O}_{7}$ coordination sphere, resulting in a geometry of distorted muffin $\left(C_{s}\right)$ (Fig. 4b) with SHAPE software ${ }^{58}$ (Table S4). Structurally, the major difference of complex $\mathbf{3}$ compare to $\mathbf{2}$ is the coordinating solvent molecules, leading to different local environments on Dy III ion, which turns out to remarkably affect the magnetic behaviour (see below). ${ }^{32}, 59$ The Dy-O and Dy- $\mathrm{N}$ distances fall in the range of 2.354(4)-2.611(5) $\AA$ and 2.480(4)2.515(5) $\AA$, respectively.
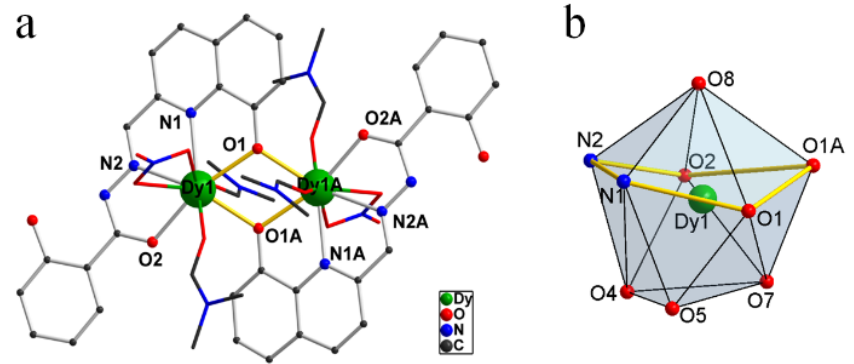

Fig. 4 a) Molecular structure of $\mathbf{3}$ with solvents and hydrogen atoms omitted for clarity. (b) Coordination polyhedra observed in 3, a distorted muffin for Dy1 and Dy2. Symmetry codes: A, -x, $-y+1,-z+1$.

Crystal structure of $\mathbf{4}$. Complex $\mathbf{4}$ is isolated from the slow evaporation of the filtrate from the same reaction of complex 3 in one week. It crystallizes in monoclinic space group $\mathrm{C2} / \mathrm{c}$ with $Z=4$ and its partially labelled structure is illustrated in Fig. 5a. A [2×2] grid arrangement forms via four dysprosium centres assembled by four fully deprotonated ligands $\mathrm{L}^{3-}$ arranged in antiparallel pairs above and below the metallic pseudo-plane (Fig. 5c). Adjacent Dy"l' ions are bridged by enolic oxygen ( $\mathrm{O} 2$ and O5) and phenoxo oxygen atoms (06 and O3) from four ligands with the $3.1_{1} 2_{12} 2_{23} 1_{1} 1_{1}$ bridging mode (Scheme $2 \mathrm{c}$ ), which form a $\left[\mathrm{Dy}_{4}\left(\mu_{2}-\mathrm{O}\right)_{8}\right]$ central core (Fig. $\left.5 \mathrm{~b}\right)$ with Dy-O-Dy angles falling in the range $109.6(3)-114.5(3)^{\circ}$ and average Dy $\cdots$ Dy distance of $3.912 \AA$ A . All eight-coordinate Dy ions have a $\mathrm{N}_{2} \mathrm{O}_{6}$ coordination sphere, adopting a triangular dodecahedral geometry $\left(D_{2 d}\right)$ (Fig. $5 \mathrm{~d}$ ) and the remaining sphere is completed by a methanol molecule. The average Dy-N and Dy-O distances are 2.496 and $2.354 \AA$, respectively. The close inspection of the crystal packing arrangements exhibits a channel containing the coordinated methanol molecules and aromatic rings of $\mathrm{L}^{3-}$ or was considered as a bigger [ $2 \times 2$ ] grid with the whole $\mathrm{Dy}_{4}$ molecule as the vertex (Fig. S2).

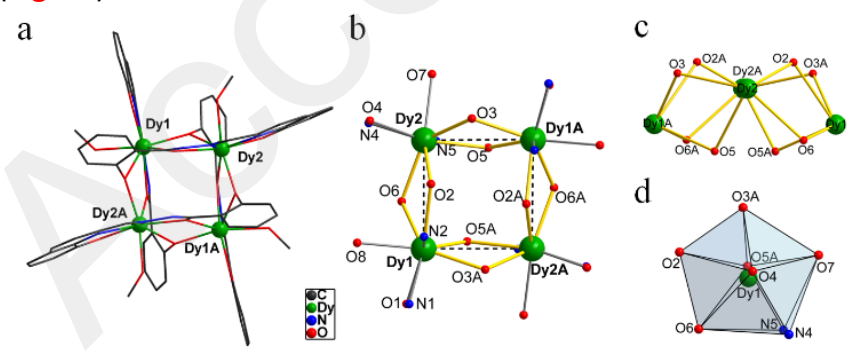

Fig. 5 a) Partially labeled structure of $\mathbf{4}$ with solvents and hydrogen atoms omitted for clarity; b) Top view of coordination environment around the Dy'll ions in 4 ; c) Side view of the nonplanar $\mathrm{Dy}_{4}$ core; d) Coordination polyhedron of Dy1 with a distorted triangular dodecahedral geometry. Symmetry codes: A, $-x, y,-z+3 / 2$

Crystal structure of $\mathbf{5}$. A synthesis similar to that of $\mathbf{2}$ except that $\mathrm{Et}_{3} \mathrm{~N}$ and $\mathrm{CH}_{3} \mathrm{OH} / \mathrm{CH}_{2} \mathrm{Cl}_{2}$ were replaced by $\mathrm{NaHCO}$ and $\mathrm{CH}_{3} \mathrm{OH} / \mathrm{CH}_{3} \mathrm{CN}$ leads to red needle crystals of complex 5 after two weeks which crystallizes in the triclinic space group $P \overline{1}$ with $Z=2$. As shown in Fig. 6 a, the structure is arranged in a nearly linear one-dimensional (1D) chain composed of $\mathrm{Dy}_{4}$ asymmetric units (Fig. 6b) which can be regarded as two similar $\mathrm{Dy}_{2}$ subunits. Within the $\mathrm{Dy}_{2}$ subunits, the dysprosium centres are held together by two quinolinic oxygen groups ( $\mathrm{O} 1$ and 04$)$ of two $\mathrm{HL}^{2-}$ ligands in an antiparallel fashion and a $\eta^{1}: \eta^{1}: \mu_{2^{-}}$ benzoate bridge with the Dy...Dy distance of 3.7303(6) and 3.7494(6) A, respectively. The required environment of Dy 1 and Dy3 are completed by a bidentated benzoate ion, while the remaining sites of Dy2 and Dy4 are methanol and water molecules, respectively, affording the prime difference between the two Dy 2 subunits. Each Dy"ll ion has a $\mathrm{N}_{2} \mathrm{O}_{6}$ coordination sphere, with Dy- $\mathrm{N}$ and Dy-O distances in the range 2.455(6)-2.519(7) $\AA$ and 2.262(5)-2.481(6) $\AA$, respectively. It's worth noting that conformational flexibility of ligands $\mathrm{HL}^{2-}$ (as a result of $\mathrm{C}-\mathrm{C}$ rotation between $\mathrm{C} 11-\mathrm{C} 12$ and $\mathrm{C} 45-\mathrm{C} 46)$ functions as a long-distance linkage in $3.2_{12} 1_{2} 1_{3} 1_{2} 1_{2}$ mode (Scheme $2 \mathrm{~d}$ ) and facilitates extension of the molecular size from $D y_{2}$ units to an infinite 1D polymer. Furthermore, a detailed analysis of the crystal packing of 5 reveals that these 1D chains are connected to engender a 2D supramolecular architecture by means of weak $\pi-\pi$ stacking interactions between two phenyl rings of coordinated benzoate group with the distance between two centroids defined by phenyl ring of $3.9 \AA$ and the dihedral angle equal to $16.7^{\circ}$ (Fig. S3). The determination of the exact geometry of the Dy"ll centres was ascertained by continuous shape measures analysis in SHAPE software. It reveals that Dy1 and Dy3 exhibit an intermediate geometry between biaugmented trigonal prism $\left(C_{2 v}\right)$ and triangular dodecahedron $\left(D_{2 \mathrm{~d}}\right)$, while the actual geometry around Dy2 and Dy4 is among triangular dodecahedron $\left(D_{2 \mathrm{~d}}\right)$, snub disphenoid $\left(D_{2 \mathrm{~d}}\right)$ and biaugmented trigonal prism $\left(C_{2 v}\right)$ (Table S3).

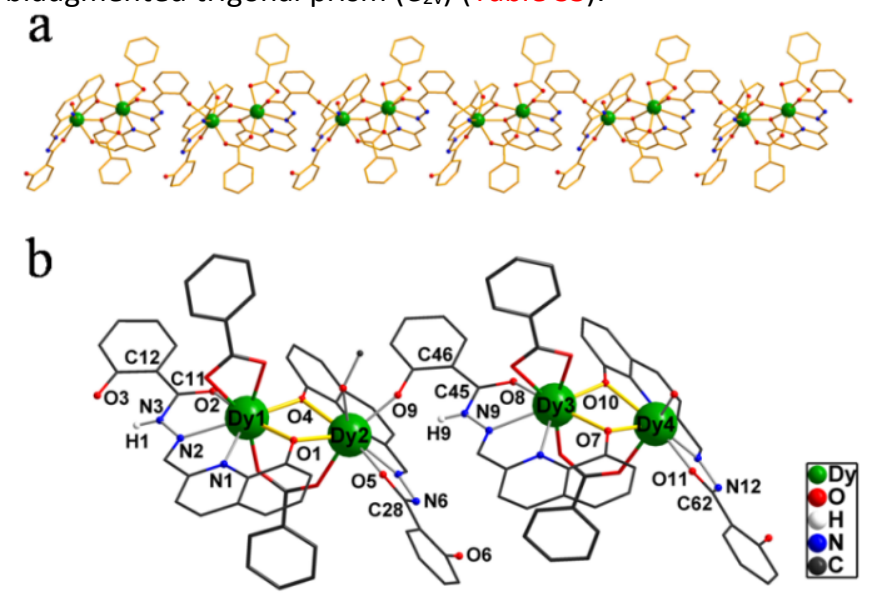

Fig. 6 a) 1D linear chain structure of $\mathbf{5}$ running along a axis with solvents and hydrogen atoms omitted for clarity; b) Structure of the $\mathrm{Dy}_{4}$ asymmetric unit of $\mathbf{5}$. 
Static Magnetic Properties. The direct current (dc) magnetic susceptibilities of all five complexes were investigated under a $1 \mathrm{kOe}$ field over the temperature range 2-300 K. As shown in Fig. $7 a$, the observed $\chi_{\mathrm{M}} T$ product for 1 at $300 \mathrm{~K}$ is $13.68 \mathrm{~cm}^{3} \mathrm{~K} \mathrm{~mol}$ 1 , in agreement with the theoretical value of ${ }^{6} \mathrm{H}_{15 / 2}$ ground state of Dylll ion $\left(S=5 / 2, L=5,{ }^{6} \mathrm{H}_{15 / 2}, g=4 / 3\right)$. The $\chi_{M} T$ value demonstrates a slight drop on lowering the temperature, which can be attributed to the thermally depopulation of excited Stark sublevels of anisotropic Dy'II ion. Then the value declines sharply down to $2.0 \mathrm{~K}$, reaching a minimum value of $10.42 \mathrm{~cm}^{3} \mathrm{~K} \mathrm{~mol}^{-1}$, suggesting possible intermolecular magnetic interactions.

Variable temperature dc magnetic data for $\mathbf{2}$ and $\mathbf{3}$ (Fig. 7b) reveal reasonable $\chi_{\mathrm{M}} T$ values of 31.85 and $29.24 \mathrm{~cm}^{3} \mathrm{~K} \mathrm{~mol}^{-1}$ at $300 \mathrm{~K}$ for two uncoupled Dy"II ions $\left(S=5 / 2, \mathrm{~L}=5,{ }^{6} \mathrm{H}_{15 / 2}, \mathrm{~g}=4 / 3\right)$. For 2, The $\chi_{\mathrm{M}} T$ product remains relatively constant above $50 \mathrm{~K}$ and shows a rapid drop at lower temperatures to $21.85 \mathrm{~cm}^{3} \mathrm{~K}$ $\mathrm{mol}^{-1}$ at $2 \mathrm{~K}$, which is mostly ascribed to the thermal depopulation of Stark sublevels and possible intramolecular antiferromagnetic interactions. In contrast, the roughly invariable $\chi_{\mathrm{M}} T$ product above $26 \mathrm{~K}$ was followed by a sharp increase to a maximum value of $33.24 \mathrm{~cm}^{3} \mathrm{~K} \mathrm{~mol}^{-1}$ at $2 \mathrm{~K}$ for 3 , indicating the presence of strongly ferromagnetic interaction between the Dy'll spin carriers. ${ }^{57}$ The distinct static magnetic behaviors are derived from the changes of local coordination environments around Dy ions. The detailed investigations are discussed in the quantum chemical calculations Section (vide infra).
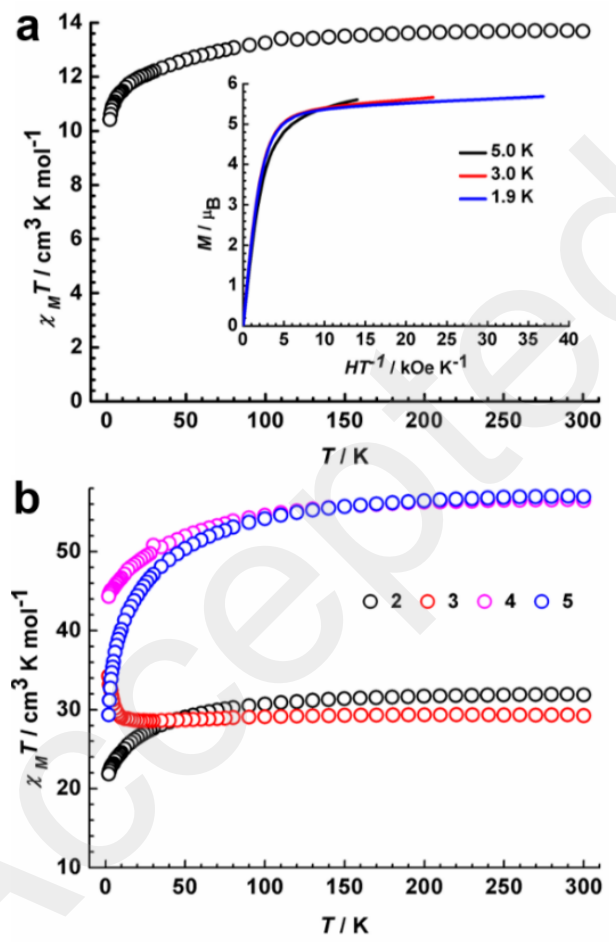

Fig. 7 a) Temperature dependence of the $\chi_{\mathrm{M}} T$ product at 1000 Oe for 1. Inset: $M$ vs. $H / T$ plots for 1 at low temperatures. b) Temperature dependence of the $\chi_{\mathrm{M}} T$ products at 1000 Oe for $\mathbf{2 -}$ 5.
For 4 and 5, the observed $\chi_{\mathrm{M}} T$ products at room temperature are 56.45 and $56.91 \mathrm{~cm}^{3} \mathrm{~K} \mathrm{~mol}^{-1}$, exactly consistent with the expected value of $56.68 \mathrm{~cm}^{3} \mathrm{~K} \mathrm{~mol}^{-1}$ for four non-interacting Dy'll ions. Upon lowering the temperature, both values of $\chi_{\mathrm{M}} T$ gently decrease until approximately $70 \mathrm{~K}$, while $\chi_{\mathrm{M}} T$ of 5 decreases faster than that of $\mathbf{4}$ at lower temperatures, to reach a value of 44.33 and $29.34 \mathrm{~cm}^{3} \mathrm{~K} \mathrm{~mol}^{-1}$ at $2 \mathrm{~K}$ for 4 and 5 , respectively.

$M$ versus $H / T$ data (inset of Fig. 7top and Fig. S4 in the Supporting Information) for complexes 1-5 are far from reaching saturation in the $0-70 \mathrm{kOe}$ field range and the corresponding magnetization data do not lie on a single mastercurve below $5 \mathrm{~K}$, confirming the presence of significant magneto-anisotropy and/or low lying excited states in all systems. ${ }^{60}$
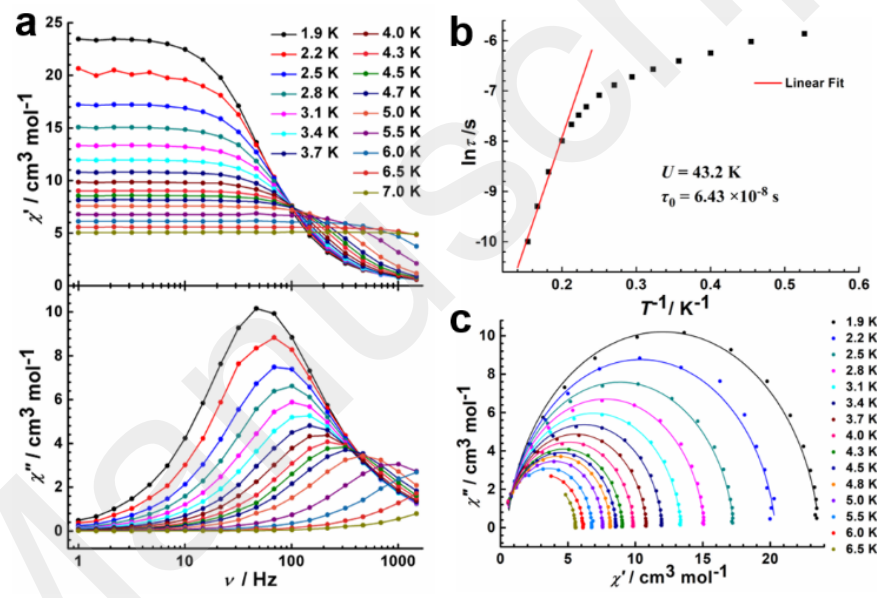

Fig. 8 a) Frequency and temperature dependence of the inphase (top) and out-of-phase (bottom) ac susceptibility of $\mathbf{3}$ under zero dc field. b) Magnetization relaxation time, In $\tau$ versus $T^{-1}$ (Arrhenius plot using ac data) for $\mathbf{3}$ under zero dc field. The solid line corresponds to the fit. c) Cole-Cole plots measured at 1.9-6.5 K under zero dc field, with the best fit to the generalized Debye model.

Dynamic Magnetic Properties. Alternating current (ac) susceptibility measurements were carried out for 1-5 under zero dc field to gain insight into the dynamics of magnetization using a 3 Oe oscillating ac field. As indicated by the temperature-dependent ac susceptibility data (Fig. S5), complexes 1, 2, 4 and 5 do not display any out-of-phase ac signal, implying a very fast relaxation of magnetization as a result of fast zero-field quantum tunneling of the magnetization (QTM). However, a significant sharp peak around an external dc field of 600 Oe where the QTM is minimized is clearly observed at $997 \mathrm{~Hz}$ and $2 \mathrm{~K}$ for complex 1, as seen from preliminary fielddependent ac measurements (Fig. S6). The application of an optimal field $H=600$ Oe thus induces the appearance of temperature-dependent signals of out-of-phase ac susceptibility ( $\chi^{\prime \prime}$ ) below $8 \mathrm{~K}$ for 1 (Fig. S7), suggesting fieldinduced slow relaxation of magnetization. ${ }^{34,61-64}$ Because of the lack of out-of-phase maxima above the temperature of $1.9 \mathrm{~K}$ for 1, which is the lowest limit of our magnetometer, we plotted $\ln \left(\chi^{\prime \prime} / \chi^{\prime}\right)$ vs. $1 / T$ over the frequency range $3-1200 \mathrm{~Hz}$ and extracted the estimated activation energy $E_{\mathrm{a}}=4.9 \mathrm{~K}$ and 
characteristic times $\tau_{0}=2.2 \times 10^{-5} \mathrm{~s}$ by applying linear fits (Fig. S8). ${ }^{65}$ This method is reasonable with the assumption that there is only one characteristic relaxation process of the Debye type with one barrier and one time constant, which had been applied earlier to the $\mathrm{Mn}_{12}$ acetate system. ${ }^{66}$

As shown in Fig. 8, both in-phase $\left(\chi^{\prime}\right)$ and out-of-phase $\left(\chi^{\prime \prime}\right)$ ac susceptibilities are strongly frequency and temperature dependent where the $\chi$ " component clearly exhibits a frequency dependence maximum for $\mathbf{3}$ in the absence of dc field, indicating the blocking behavior of magnetization characteristic for SMMs. ${ }^{57}$ The relaxation times were extracted from the fitting of frequency-dependent $\chi^{\prime \prime}$ susceptibility in the range of 1.9-6.5 $\mathrm{K}$ using the generalized Debye model (Table S5), and were plotted as a function of $1 / T$ (Fig. 8). The fitting of the hightemperature data $(5.0$ to $6.5 \mathrm{~K})$ with the Arrhenius law $(\tau=$ $\left.\tau_{0} \exp \left(U_{\text {eff }} / \mathrm{k}_{\mathrm{B}} T\right)\right)$ gives an energy gap of $43.2 \mathrm{~K}$ and a preexponential factor of $6.43 \times 10^{-8} \mathrm{~s}$, which is typical of Orbach relaxation process. We note, however, relaxation times deviate from the linearity and trace out an exponential growth at $\mathrm{T}<5.0$ $\mathrm{K}$, suggesting the occurrence of other phonon-assisted relaxation processes. ${ }^{57}$ The Cole-Cole plots (Fig. 8) shows a nicely symmetrical semicircular shape in the range of $1.9 \mathrm{~K}-6.5$ $\mathrm{K}$ and can be fitted to the generalized Debye model, yielding $\alpha$ parameters of $0.019-0.084$, suggesting a fairly narrow distribution of relaxation time at different temperatures.

Quantum Chemical Calculations. In order to get insight into the interrelationship of magnetic anisotropy, magnetic coupling interactions and SMM properties, ab initio SA-CASSCF/RASSI-SO (see Computational details in $\mathrm{SI}$ ) on the basis of X-ray determined structures of complexes $\mathbf{2}, \mathbf{3}$ and three other $\mathrm{Dy}_{2}$ complexes, namely $\quad\left[\mathrm{Dy}_{2}\left(\mathrm{H}_{2} \mathrm{O}\right)_{2}\left(\mathrm{NO}_{3}\right)_{2}\left(\mathrm{~L}_{1}\right)_{2}\right] \quad$ (6), $\left[\mathrm{Dy}_{2}\left(\mathrm{CH}_{3} \mathrm{OH}\right)_{2}(\mathrm{PhCOO})_{2}\left(\mathrm{~L}_{2}\right)_{2}\right](7)$ and $\left[\mathrm{Dy}_{2}\left(\mathrm{NO}_{3}\right)_{2}\left(\mathrm{~L}_{3}\right)_{2}\right](8)$ (Fig. S9). These last compounds that contain different types of ligands (Scheme 3) were previously described.25, 57, 67 The crystal field energy splitting and their corresponding $g$ factors are listed in Tables S6-10. A highly uniaxial anisotropy indicated by $g_{z}>19.20$ ( $g_{z}=20$ for a pure ${ }^{6} \mathrm{H}_{15 / 2}$ ground multiplet) is found for all complexes, but the slightly lower transverse components of anisotropy $\left(g_{\mathrm{x}}, g_{\mathrm{y}}\right)$ on the ground doublet states of complexes $\mathbf{3}$, 6 , and 7 could explain the occurrence of SMM behaviours as a result of less mixing microstates which slow down the quantum
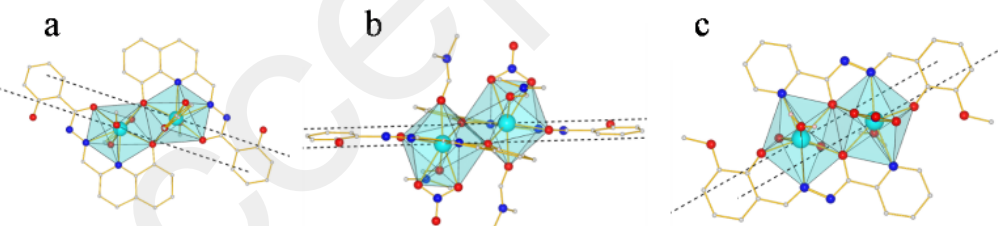

tunneling relaxation of magnetization. Despite the terminal solvent molecules and anions, the anisotropy axes of Dy centers in all complexes almost completely lie within the $\mathrm{Dy}_{2} \mathrm{O}_{2}$ plane formed via the coordination of two antiparallel ligands with two Dy ions while the directions are determined by charge distribution on the ligands, which is consistent with the electrostatic model developed by Long. ${ }^{11}$ Here mapping the molecular electrostatic potential provides a powerful visualization of the effect of charge distribution on ligands on determining anisotropy properties of Dy centres (Fig. 9). As shown in Scheme 3, the four ligands demonstrate different charge distribution and bridging donors which specially contain deprotonated enolic, quinolinic/phenoxo, and alkoxido oxygen donors showing the gradually increasing electron-donating ability, but it is also of importance to identify the terminal and bridging coordinate atoms which exhibit different electrostatic effects, i.e. the terminal charge has stronger electrostatic effects than bridging one in the same situation. Apparently in complexes 6 and 7 the bond to terminal phenoxo oxygen atom dominates the crystal field, thus leading to the lowest electrostatic potential and the resultant preferential direction of anisotropic axis, as shown in Fig. 9. Interestingly, in comparison with enolic bridging oxygen atoms in complex 6 the stronger electron-donating ability of alkoxido oxygen bridges in complex 7 generates other low potential sites on the axial direction which efficiently improves the uniaxiality and crystal field splitting on Dy ions indicated by the lower $g_{x}$ and $g_{y}$ factors as well as the larger total energy separation (Tables S8, S9). As a result, complex 7 shows the best SMM behaviour with the highest effective barrier, $U_{\text {eff }}=94 \mathrm{~K}\left(U_{\text {eff }}=69 \mathrm{~K}\right.$ for complex 6$)$. In contrast, the quinolinic oxygen atoms on ligand $\mathrm{L}^{2-}$ play the bridging role while the terminal enolic oxygen delivers relatively weak bonding interaction to Dy center in complexes $\mathbf{2}$ and $\mathbf{3}$, thus weakening the uniaxiality of crystal field compared with that in complexes 6 and 7 (Tables S6, S7), which is evidenced by the average distribution of electrostatic potential on the coordination spheres of Dy ions. Such effects appear more pronounced when the phenol group in $\mathrm{L}_{2}{ }^{2-}$ is substituted by pyridyl group to $\mathrm{L}_{3}^{-}$in Fig. 9 owing to the disappearance of terminal charge. It is shown that the lowest electrostatic potential site disappears on the site of pyridyl nitrogen site.
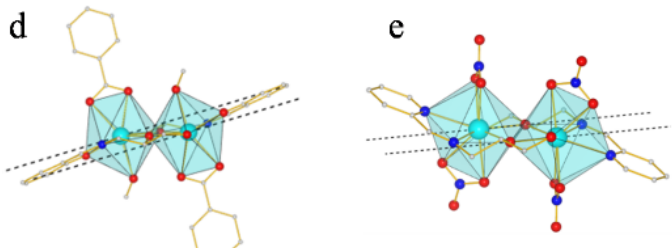
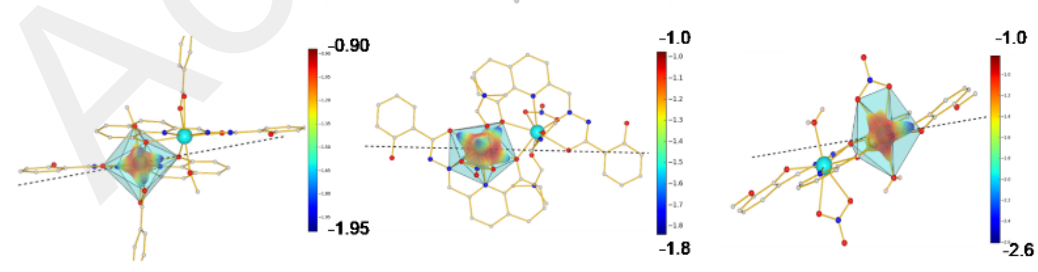

Fig. 9 The $g_{z}$ axial directions (top) and molecular electrostatic potential (bottom) computed for the ground states KD of complexes 2 (a), 3 (b), 6 (c), 7 (d), 8 (e). See Computational details in SI. 


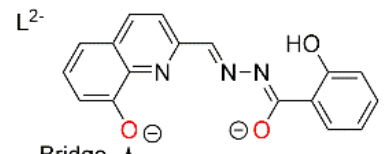
Bridge $\uparrow$

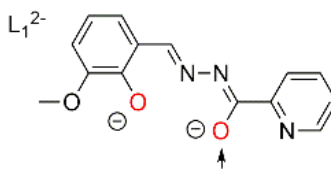

$\mathrm{L}_{2}^{2}$

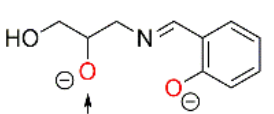

Scheme 3 The charge distribution on four different kinds of Schiff-base ligands. The arrows indicate the bridging donors.

Since the above calculations are not able to describe the lowtemperature static magnetic behaviour of these complexes which demonstrate different magnetic coupling interactions between Dy centres based on $\chi_{\mathrm{M}} T$ vs. $T$ plots, the intramolecular magnetic interactions are considered in the calculations within the Lines model with an effective spin $s=1 / 2$ for each magnetic centre, as implemented in the POLY_ANISO code, $\hat{\boldsymbol{H}}=J_{\mathrm{dip}} \hat{\boldsymbol{s}}_{1} \hat{\boldsymbol{s}}_{2}+$ $J_{\text {exch }} \hat{\boldsymbol{s}}_{1} \hat{\boldsymbol{s}}_{2}$. The exchange Hamiltonian is built on the basis of the ground state Kramers Doublet (KD) of the Dy"ll centre leading to $2^{2}=4$ exchange states ( 2 KDs). The intermolecular magnetic interactions are neglected due to the large distances between the $\left[D y_{2}\right]$ dimers. In a first attempt to describe these interactions, only the dipolar term, $J_{\text {dip }}$, is computed (Fig. S1014 , green curves) which is associated with the Dy...Dy distances and the calculated orientations of main anisotropy axes and $g$ tensors. As one can see, all dimers exhibit ferromagnetic dipolar coupling terms $\left(J_{\text {dip }}>0\right)$ with a narrow range of magnitude from 0.94 to $1.37 \mathrm{~cm}^{-1}$ (Table 1 ) owing to their similar directions of main anisotropic axes and the small deviation angles from Dy...Dy connecting line. In contrast, a qualitative picture of the exchange term, $J_{\text {exch, }}$ is realized through a fitting to obtain the best agreement with experimental data (Fig. S10-14, red curves). A description of the exchange states is given in Table S11, and the values of $J_{\text {dip }}, J_{\text {exch, }}$, and $J_{\text {total }}$ are listed in Table 1 . In complexes 3, 6, and 7 the ferromagnetic $J_{\text {dip }}$ terms are balanced using small antiferromagnetic $J_{\text {exch }}$ terms, thus leading to the observed ferromagnetic interactions $\left(J_{\text {total }}>0\right)$, while a stronger antiferromagnetic $J_{\text {exch }}$ term is required to be able to stabilize the antiferromagnetic configuration in complexes $\mathbf{2}$ and $\mathbf{8}$, respectively. A closer look at structural details reveals that the stronger antiferromagnetic exchange interaction in complexes $\mathbf{2}$ and $\mathbf{8}$ is mainly related with the larger angles of easy axes to Dy...Dy connecting line which can modulate the superexchange path between two Dy centres in terms of similar Dy-O-Dy angles in all complexes. Furthermore, the Dy...Dy distances is also affecting the magnitude of $J_{\text {exch }}$ term, i.e. the antiferromagnetic interaction is gradually improved from 3, 6, to 7 with the decreasing Dy...Dy distances.

Table 1 Intramolecular distances, angles and magnetic interaction constants. (*The angles between easy axes and Dy...Dy connecting line)

\begin{tabular}{|c|c|c|c|c|c|}
\hline complexes & 2 & 3 & 6 & 7 & 8 \\
\hline Dy $\cdots$ Dy/ Å & 3.8 & 3.95 & 3.83 & 3.77 & 3.73 \\
\hline Dy-O-Dy/ & 108 & 112 & 110 & 112 & 112 \\
\hline$g_{\mathrm{z}}$ angle $* /^{\circ}$ & 30 & 21 & 22 & 18 & 29 \\
\hline$J_{\text {dip }} / \mathrm{cm}^{-1}$ & 0.94 & 1.08 & 1.19 & 1.37 & 1.01 \\
\hline$J_{\text {exch }} / \mathrm{cm}^{-1}$ & -1.20 & -0.29 & -0.59 & -0.66 & -1.08 \\
\hline$J_{\text {total }} / \mathrm{cm}^{-1}$ & -0.26 & 0.79 & 0.6 & 0.71 & -0.07 \\
\hline
\end{tabular}

\section{Conclusions}

The versatile ligand $\mathrm{H}_{3} \mathrm{~L}$ combining the 8-hydroxyquinoline unit with the multidentate hydrazone ligand was rationally designed by us to construct the novel multinuclear lanthanide SMMs, and the resulting complexes vary from unique mononuclear, dinuclear, grid-like tetranuclear to linear 1D chain. Their formations are largely ascribed to the versatile and flexible coordination modes of phenoxo groups from salicylic hydrazide depending on reaction conditions. The presented results confirm that the elaborate design of ligand $\mathrm{H}_{3} \mathrm{~L}$ provide an extremely effective strategy for preparation of new molecular architectures with novel type of metal topologies. Furthermore, the magnetic measurements were performed on all complexes. In particular, it provides the opportunity to get insight into the interrelationship of magnetic anisotropy, magnetic coupling interactions and SMM properties, when the dinuclear complexes $\mathbf{2}$ and $\mathbf{3}$ are compared with three other $\mathrm{Dy}_{2}$ complexes $(\mathbf{6}, \mathbf{7}, \mathbf{8})$ with another two kinds of similar Schiff-base ligands showing the different bridging donors and charge distribution. Therefore, detailed ab initio calculations and electrostatic potential analysis reveal that the anisotropic electronic structures of Dy ions indicated by $g$ factors and axial directions are associated with charge distribution on those ligands, which further determines the magnetic coupling interactions including dipolar and exchange terms, $J_{\text {dip }}$ and $J_{\text {exch, }}$, between Dy centres and the resultant SMM behaviours of different complexes. This work presents a promising example for understanding the relationship between the anisotropic electronic structures and charge distribution on the ligands, thus offers new strategies for modulating the behavior of SMMs.

\section{Conflicts of interest}

There are no conflicts to declare.

\section{Acknowledgements}

We thank the National Natural Science Foundation of China (Grant 21871247) and Key Research Program of Frontier Sciences, CAS (Grant ZDBS-LY-SLH023) for financial support. J. T. gratefully acknowledges support of the Royal Society-Newton Advanced Fellowship (NA160075). L. Z. is grateful for the 
support through the $66^{\text {th }}$ China Postdoctoral Science Foundation Funded Project (2019M663946XB). V. M. and B. L. G. thank the French GENCI/IDRIS-CINES centres for high-performance computing resources.

\section{Notes and references}

1. J. D. Rinehart, M. Fang, W. J. Evans and J. R. Long, Nat. Chem., 2011, 3, 538-542.

2. A. Dei and D. Gatteschi, Angew. Chem. Int. Ed., 2011, 50, 1185211858.

3. G. Christou, D. Gatteschi, D. N. Hendrickson and R. Sessoli, MRS Bull., 2000, 25, 66-71.

4. R. Sessoli, D. Gatteschi, A. Caneschi and M. A. Novak, Nature, 1993, 365, 141-143.

5. J. Tang, I. Hewitt, N. T. Madhu, G. Chastanet, W. Wernsdorfer, C. E. Anson, C. Benelli, R. Sessoli and A. K. Powell, Angew. Chem. Int. Ed., 2006, 45, 1729-1733.

6. P. Zhang, Y.-N. Guo and J. Tang, Coord. Chem. Rev., 2013, 257, 1728-1763.

7. P. Zhang, L. Zhang, C. Wang, S. Xue, S.-Y. Lin and J. Tang, J. Am. Chem. Soc., 2014, 136, 4484-4487.

8. J. D. Rinehart, M. Fang, W. J. Evans and J. R. Long, J. Am. Chem. Soc., 2011, 133, 14236-14239.

9. N. Ishikawa, M. Sugita, T. Ishikawa, S.-y. Koshihara and Y. Kaizu, J. Am. Chem. Soc., 2003, 125, 8694-8695.

10. C. Benelli and D. Gatteschi, Chem. Rev., 2002, 102, 2369-2388.

11. J. D. Rinehart and J. R. Long, Chem. Sci., 2011, 2, 2078-2085.

12. L. Norel, L. E. Darago, B. Le Guennic, K. Chakarawet, M. I. Gonzalez, J. H. Olshansky, S. Rigaut and J. R. Long, Angew. Chem., Int. Ed., 2018, 57, 1933-1938.

13. C. A. P. Goodwin, F. Ortu, D. Reta, N. F. Chilton and D. P. Mills, Nature, 2017, 548, 439-442.

14. L. Ungur, S.-Y. Lin, J. Tang and L. F. Chibotaru, Chem. Soc. Rev., 2014, 43, 6894-6905.

15. Y.-N. Guo, L. Ungur, G. E. Granroth, A. K. Powell, C. Wu, S. E. Nagler, J. Tang, L. F. Chibotaru and D. Cui, Sci. Rep., 2014, 4, 5471.

16. D. N. Woodruff, R. E. P. Winpenny and R. A. Layfield, Chem. Rev., 2013, 113, 5110-5148.

17. I. J. Hewitt, J. Tang, N. T. Madhu, C. E. Anson, Y. Lan, J. Luzon, M. Etienne, R. Sessoli and A. K. Powell, Angew. Chem. Int. Ed., 2010, 49, 6352-6356.

18. S.-Y. Lin, W. Wernsdorfer, L. Ungur, A. K. Powell, Y.-N. Guo, J. Tang, L. Zhao, L. F. Chibotaru and H.-J. Zhang, Angew. Chem. Int. Ed. 2012, 51, 12767-12771.

19. S. D. Jiang, B. W. Wang, G. Su, Z. M. Wang and S. Gao, Angew. Chem. Int. Ed., 2010, 49, 7448-7451.

20. R. J. Blagg, C. A. Muryn, E. J. L. Mclnnes, F. Tuna and R. E. P. Winpenny, Angew. Chem., Int. Ed., 2011, 50, 6530-6533.

21. R. J. Blagg, L. Ungur, F. Tuna, J. Speak, P. Comar, D. Collison, W. Wernsdorfer, E. J. L. Mclnnes, L. F. Chibotaru and R. E. P. Winpenny, Nat. Chem., 2013, 5, 673-678.

22. F.-S. Guo, B. M. Day, Y.-C. Chen, M.-L. Tong, A. Mansikkamäki and R. A. Layfield, Science, 2018, 362, 1400-1403.

23. H. Wu, M. Li, Z. Xia, V. Montigaud, O. Cador, B. Le Guennic, H. Ke, W. Wang, G. Xie, S. Chen and S. Gao, Chem. Commun., 2021, 57 371-374.

24. J.-B. Peng, Q.-C. Zhang, X.-J. Kong, Y.-Z. Zheng, Y.-P. Ren, L.-S. Long, R.-B. Huang, L.-S. Zheng and Z. Zheng, J. Am. Chem. Soc., 2012, 134, 3314-3317.
25. P. Zhang, L. Zhang, S.-Y. Lin, S. Xue and J. Tang, Inorg. Chem., 2013, 52, 4587-4592.

26. F. Tuna, C. A. Smith, M. Bodensteiner, L. Ungur, L. F. Chibotaru, E. J. L. Mclnnes, R. E. P. Winpenny, D. Collison and R. A. Layfield, Angew. Chem., Int. Ed., 2012, 51, 6976-6980.

27. S.-Y. Lin, Y.-N. Guo, Y. Guo, L. Zhao, P. Zhang, H. Ke and J. Tang, Chem. Commun., 2012, 48, 6924-6926.

28.G. Fernandez Garcia, D. Guettas, V. Montigaud, P. Larini, R. Sessoli, F. Totti, O. Cador, G. Pilet and B. Le Guennic, Angew. Chem., Int. Ed., 2018, 57, 17089-17093.

29. Y. J. Gao, G. F. Xu, L. Zhao, J. Tang and Z. L. Liu, Inorg. Chem., 2009, 48, 11495-11497.

30. V. Chandrasekhar, S. Hossain, S. Das, S. Biswas and J.-P. Sutter Inorg. Chem., 2013, 52, 6346-6353.

31.P.-H. Guo, J.-L. Liu, Z.-M. Zhang, L. Ungur, L. F. Chibotaru, J.-D. Leng, F.-S. Guo and M.-L. Tong, Inorg. Chem., 2012, 51, 1233-1235.

32. P.-H. Lin, T. J. Burchell, L. Ungur, L. F. Chibotaru, W. Wernsdorfer and M. Murugesu, Angew. Chem., Int. Ed., 2009, 48, 9489-9492.

33. Y.-Z. Zheng, Y. Lan, C. E. Anson and A. K. Powell, Inorg. Chem., 2008, 47, 10813-10815.

34. L. Zhang, P. Zhang, L. Zhao, S.-Y. Lin, S. Xue, J. Tang and Z. Liu, Eur. J. Inorg. Chem., 2013, 1351-1357.

35. P.-H. Lin, I. Korobkov, W. Wernsdorfer, L. Ungur, L. F. Chibotaru and M. Murugesu, Eur. J. Inorg. Chem., 2011, 1535-1539.

36. D. T. Thielemann, A. T. Wagner, Y. Lan, C. E. Anson, M. T. Gamer, A. K. Powell and P. W. Roesky, Dalton Trans., 2013, 42, $14794-$ 14800.

37. J. Lu, V. Montigaud, O. Cador, J. Wu, L. Zhao, X.-L. Li, M. Guo, B. Le Guennic and J. Tang, Inorg. Chem., 2019, 58, 11903-11911.

38. L. Ungur, S. K. Langley, T. N. Hooper, B. Moubaraki, E. K. Brechin, K. S. Murray and L. F. Chibotaru, J. Am. Chem. Soc., 2012, 134, 18554-18557.

39. L. Zhao, S. Xue and J. Tang, Inorg. Chem., 2012, 51, 5994-5996.

40. F. Houard, Q. Evrard, G. Calvez, Y. Suffren, C. Daiguebonne, O. Guillou, F. Gendron, B. Le Guennic, T. Guizouarn, V. Dorcet, M. Mannini and K. Bernot, Angew. Chem., Int. Ed., 2020, 59, 780-784.

41. P. Zhang, L. Zhang and J. Tang, Curr. Inorg. Chem., 2013, 3, 101111.

42. S. Xue, L. Zhao, Y.-N. Guo, X.-H. Chen and J. Tang, Chem. Commun. 2012, 48, 7031-7033.

43. M. D. Taylor, C. P. Carter and C. I. Wynter, J. Inorg. Nucl. Chem., 1968, 30, 1503-1511.

44. G. A. Bain and J. F. Berry, J. Chem. Educ., 2008, 85, 532-536.

45. G. M. Sheldrick, SHELXS-97, Program for Crystal Structure Solution, University of Göttingen, Germany, 1997.

46. O. V. Dolomanov, L. J. Bourhis, R. J. Gildea, J. A. K. Howard and H. Puschmann, J. Appl. Crystallogr., 2009, 42, 339-341.

47. Y.-C. Liu and Z.-Y. Yang, Eur. J. Med. Chem., 2009, 44, 5080-5089.

48. R. A. Coxall, S. G. Harris, D. K. Henderson, S. Parsons, P. A. Tasker and R. E. P. Winpenny, J. Chem. Soc., Dalton Trans., 2000, 23492356.

49. Y.-N. Guo, G.-F. Xu, W. Wernsdorfer, L. Ungur, Y. Guo, J. Tang, H.-J. Zhang, L. F. Chibotaru and A. K. Powell, J. Am. Chem. Soc., 2011, 133, 11948-11951.

50. Y.-N. Guo, G.-F. Xu, P. Gamez, L. Zhao, S.-Y. Lin, R. Deng, J. Tang and H.-J. Zhang, J. Am. Chem. Soc., 2010, 132, 8538-8539.

51.S. Xue, Y.-N. Guo, L. Zhao, P. Zhang and J. Tang, Dalton Trans., 2014 43, 1564-1570.

52. M. Albrecht, M. Fiege and O. Osetska, Coord. Chem. Rev., 2008, 252, 812-824.

53. Z.-F. Yang, Y.-M. Tian, W.-Y. Zhang, P. Chen, H.-F. Li, Y.-Q. Zhang and W.-B. Sun, Dalton Trans., 2019, 48, 4931-4940. 
54. L. Zhang, P. Zhang, L. Zhao, J. Wu, M. Guo and J. Tang, Inorg. Chem., 2015, 54, 5571-5578.

55. L. Zhang, P. Zhang, L. Zhao, J. Wu, M. Guo and J. Tang, Dalton Trans., 2016, 45, 10556-10562.

56. D. Casanova, M. Llunell, P. Alemany and S. Alvarez, Chem. -Eur. J., 2005, 11, 1479-1494.

57. Y.-N. Guo, X.-H. Chen, S. Xue and J. Tang, Inorg. Chem., 2011, 50, 9705-9713.

58. A. Ruiz-Martínez, D. Casanova and S. Alvarez, Chem. -Eur. J., 2008, 14, 1291-1303.

59. L. Ungur, J. J. Le Roy, I. Korobkov, M. Murugesu and L. F. Chibotaru, Angew. Chem., Int. Ed., 2014, 53, 4413-4417.

60. P.-H. Lin, W.-B. Sun, M.-F. Yu, G.-M. Li, P.-F. Yan and M. Murugesu, Chem. Commun., 2011, 47, 10993-10995.
61. S. Das, A. Dey, S. Biswas, E. Colacio and V. Chandrasekhar, Inorg. Chem., 2014, 53, 3417-3426.

62. F. Habib, J. Long, P.-H. Lin, I. Korobkov, L. Ungur, W. Wernsdorfer, L. F. Chibotaru and M. Murugesu, Chem. Sci., 2012, 3, 2158-2164.

63. T. Fukuda, K. Matsumura and N. Ishikawa, J. Phys. Chem. A, 2013, 117, 10447-10454.

64. F. Habib, P.-H. Lin, J. Long, I. Korobkov, W. Wernsdorfer and M. Murugesu, J. Am. Chem. Soc., 2011, 133, 8830-8833.

65. J. Bartolomé, G. Filoti, V. Kuncser, G. Schinteie, V. Mereacre, C. E. Anson, A. K. Powell, D. Prodius and C. Turta, Phys. Rev. B, 2009, 80, 014430.

66. F. Luis, J. Bartolomé, J. F. Fernández, J. Tejada, J. M. Hernández, X. X. Zhang and R. Ziolo, Phys. Rev. B, 1997, 55, 11448-11456.

67. X. Wang , L.-Y. Wang, S.-Y. Wu, L.-J. Ou and G.-P. Yang, Polyhedron, 2020, 184, 114553. 


\section{SYNOPSIS TOC}

Assembly of dysprosium(III) salts with hydrazone $\mathrm{H}_{3} \mathrm{~L}$ affords a variety of molecular magnetic compounds from mononuclear, dinuclear, grid-like tetranuclear to linear 1D chain, due to the versatile and flexible coordination modes of phenoxo groups from salicylic hydrazide.

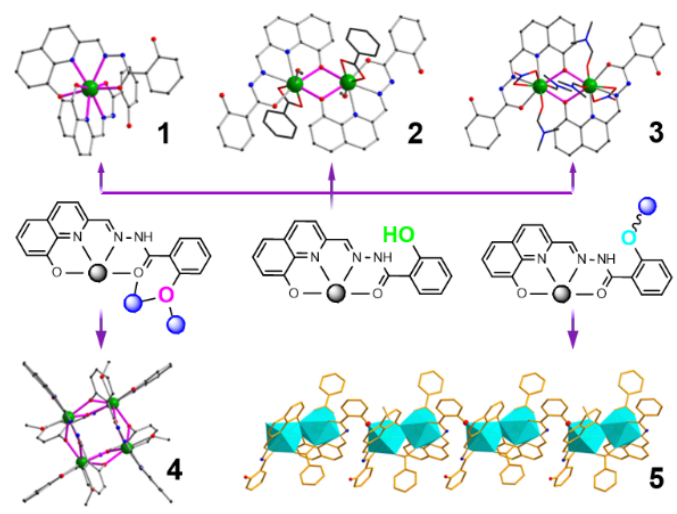

